\title{
Evolution of Payment System
}

\author{
Amith Donald Menezes ${ }^{1}$ \& Dr. Prakash Pinto ${ }^{2}$ \\ ${ }^{1}$ Srinivas Institute of Management Studies, Mangalore-575001, Karnataka, INDIA \\ ${ }^{2}$ St. Joseph Engineering College, Vamanjoor, Mangalore-575005, Karnataka, INDIA \\ E-mail: amith.menezes@yahoo.co.in
}

Type of the Paper: Review Article.

Type of Review: Peer Reviewed.

DOI: http://dx.doi.org/

\section{How to Cite this Paper:}

Menezes, Amith Donald., Pinto, Prakash. (2017). Evolution of Payment System. International Journal of Management, Technology, and Social Sciences (IJMTS), (ISSN: Applied), 2(1), 45-52.

DOI: http://dx.doi.org/

International Journal of Management, Technology, and Social Sciences (IJMTS)

(C) Srinivas Publication, India.

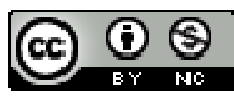

This work is licensed under a Creative Commons Attribution-Non Commercial 4.0 International License subject to proper citation to the publication source of the work.

Disclaimer: The scholarly papers as reviewed and published by the Srinivas Publications (S.P.), India are the views and opinions of their respective authors and are not the views or opinions of the SP. The SP disclaims of any harm or loss caused due to the published content to any party. 


\title{
Evolution of Payment System
}

\author{
Amith Donald Menezes ${ }^{1}$ \& Dr. Prakash Pinto ${ }^{2}$ \\ ${ }^{1}$ Srinivas Institute of Management Studies, Mangalore-575001, Karnataka, INDIA \\ ${ }^{2}$ St. Joseph Engineering College, Vamanjoor, Mangalore-575005, Karnataka, INDIA \\ E-mail: amith.menezes@yahoo.co.in
}

\begin{abstract}
Clearing has been an important part of the banking system and will always remain a part of it for years to come. Clearing in banking indicates the transfer of fund from one person to another. This clearing of fund can take place in 2 ways either through cash or through cheque. There has been no major change in the cash transactions except for the changes in value of money. However the cheque clearing system has undergone lot of changes. The origin of cheque can be traced back to the first century AD, where banks in and around Persia used to issue letters of credit called "Sakks" wherein the banks used to pay the identified payees as per the instructions. This eliminated the cumbersome process of carrying money or gold which was very risky. Changes have taken place in cheque clearing over the period of time. From ordinary cheque clearing to MICR clearing and finally to the latest in clearing 'Cheque Truncation System'.

This is a conceptual paper which tries to explore the changes that have taken place in the bank clearing system in the past, present and will also try to visualise the future of bank clearing.
\end{abstract}

Keywords: Cheque Truncation, MICR clearing.

\section{INTRODUCTION:}

Clearing in the banking or finance sector means all the activities that are done from the time a commitment has been done for a transaction up to the time of settlement of this commitment. This essentially speaks about the payment aspect of the transaction, which is the major part in settling any commitments. Payments can basically be of two types, that is either cash payment or non-cash payment. There has been no major change in Cash payment system which has been a major source of payment. The only change has been the types of currency used or the value associated with it. This is not the same with regards to the non-cash payments, which has been changing from time to time based on the need and trend in the economy. To name a few of these non- cash payment are;

- Cheques

- Electronic clearing system (ECS)

- $\quad$ Real time gross settlement (RTGS)

- $\quad$ Electronic fund transfer (EFT)
- National electronic fund transfer (NEFT)

- Card based clearing (CBC)

- $\quad$ Pre-paid payment system

- Mobile payment system

- Online payment systems

\section{OBJECTIVES:}

The main objectives of the study are to know

1. The history and evolution of cheque clearing system.

2. The types of cheque clearing or paperbased clearing in banks

\section{RESEARCH METHODOLOGY:}

Since this is a conceptual paper, the data is collected mainly through secondary sources and then analysed to meet the objectives. Also certain unstructured interviews were done with the managers of certain banks to know things in detail.

\section{NON-CASH PAYMENTS:}

Of the various non-cash payments Cheques or the paper based instrument is the major one. 
The use of paper-based instruments (like cheques and drafts etc.) accounts for nearly $60 \%$ of the volume of total non-cash transactions in the country. In value terms, the share is presently around 11\%. By going through this statistics, it is apt that we consider the changes that have taken place in the clearing system of these paper based instruments.

\section{HISTORY AND EVOLUTION OF CHEQUE CLEARING SYSTEM:}

Cheques in India were first introduced by Bank of Hindustan, a joint stock company/ bank which was established in 1770. In 1827 Post Bills were introduced by British. These were the promissory notes that were issued by the bank on a distant place, the holder would be paid on acceptance after a specified particular number of days.

In 1839, buying and selling of the bills of exchange was started by the Bank of Bengal and it became a part of business to be conducted by them. In 1881, the Negotiable instruments Act (NI Act) was passed which formalised many things including the usage and characteristics of instruments such as cheque, bill of exchange \& promissory note. This act was the legal framework for all the non-cash paper payment instruments in India. With the slow \& steady growth in the volumes of commerce and trade and the growing confidence of the public in the usage of cheques \& other paper based instruments, the transactions through these payment instruments also grew at a rapid pace. Initially the Bank employees had to frequently walk to other banks, collect cheques and drafts, and present them to the drawee banks and then collect the cash over the counter [1]. This brought into picture the risk of the instruments being lost in transit and also that this system could be viable only for a small volume of cheques.

As the banking system started developing, the volumes \& turnover of cheques also started increasing, which created the need for an organised cheque clearing \& processing system. The clearing associations were started by the banks in the presidency towns. The final settlement between member banks was done by means of cheques which were drawn upon these presidency banks. Once the
Imperial Bank was set up in 1921, the settlement was effected through cheques drawn on this bank.

The clearing house rules were first adopted by the Calcutta Clearing Banks Association in 1938. This association had 25 large banks as its members \& 8 sub members. There were 2 ordinary clearings on each business day excluding Saturday[2]. This association did not cover many other banks in Calcutta \& hence they started a group call the Metropolitan Banking Association with 50 members. The association conducted the Metropolitan Clearing House in 1939. Subsequently in 1940 they arrived at an understanding with the Calcutta Clearing House. Similarly in Bombay we had the Bombay Clearing House [1].

After the Reserve Bank of India (RBI) was set up under the RBI Act 1935, the clearing houses that were setup in the presidency towns were taken over by the RBI.

\section{TYPES OF CHEQUE CLEARING OR PAPER-BASED CLEARING IN BANKS:}

\subsection{TRADITIONAL CLEARING:}

Daily cheque clearing was initially started in 1770 wherein the bank clerks used to meet each other to exchange their cheques and settle their dues or balances if any through cash. This system was also followed in India too wherein the bank employees used to walk to other banks with the cheques provided by their customers for clearing. These cheques were presented to the respective drawee banks and the amount was collected over the counter.

\subsection{MANUAL CLEARING/ HAND SORT} CLEARING:

As discussed previously, with the formation of clearing houses in the metropolitans and other presidential towns the settlement in cash vanished \& was replaced by new system. Here the clerks or the representatives of the various banks use to meet at a central point, known as the clearing house to exchange their cheques. Once the claims on cheques were settled, the balance amount was paid by the banks through the cheques of the presidential Banks. This settlement was later changed to the respective Clearing House bank cheques or the RBI cheques. 


\subsection{CLAIM BASED SETTLEMENT SYSTEM:}

The first major step to be done in the process of modernisation of payment system was the computerisation of clearing operations. The claim based settlement system (CBSS) was introduced in the early eighties at Delhi, Mumbai and Chennai. This system used Microprocessor based computer system for generating the settlement reports which were based on the input statements which had the aggregate amount of claims or cheques presented by one bank over the other in the clearing house [3]. Due to the errors in manual sorting and balancing, the settlement \& balancing of clearing cheques used to take a lot of time. Hence this system of settlement was introduced.

\subsection{MICR CLEARING:}

The Magnetic Ink Character Recognition (MICR) system or format was first developed in 1950's by Stanford Research Institute \& General Electric Computer Laboratory[4]. This is a technology wherein the cheques are processed mechanically with enhanced speed. The existing cheques were redesigned with the introduction of 9 digit MICR codeline at the bottom of the cheque. These machine readable 9 digits MICR numbers identified its city, through its postal code. This also helped the clearing houses to sort the cheques based on the bank \& branch wise \& ultimately help the clearing house to deliver these cheques to the respective bank branches. This system was introduced in 1986 for the first time in India at Mumbai. By 1989, this MICR clearing system was fully operational in all the metropolitan cities. Subsequently by 1990's it was operational all over the country.

\subsection{INTER-CITY CLEARING:}

The 4 metro cities, Mumbai, Delhi, Chennai and Calcutta were covered by this 2 way intercity clearing. As per this system, any inter-city cheques which are drawn on any of these 4 metro cities were being processed at the MICR clearing house \& sent to the drawee centre to be integrated with the clearing of the local centre. The extension of this system to all other major cities was called as "Regional Grid Clearing”.

\subsection{MAGNETIC MEDIA BASED} CLEARING SYSTEM (MMBCS):

This is also known as floppy based clearing system. This is based on the in-house software of RBI, wherein the clearing data that is the funds cleared or returned are submitted in floppies to the clearing house and based on which the clearing is conducted. This was a step towards complete automation of the MICR cheque processing \& clearing system [5]. This system covers all the different types of clearings except inter-city clearing.

\subsection{HIGH VALUE CLEARING:}

This type of clearing was first introduced on April 1989 in Chennai. This system was used to settle large value based cheques in major cities especially the ones where RBI had its branches. The banks within a certain geographical area of the clearing house used to present cheques of large value, especially above 1 lakh within a certain cut-off time to the clearing house [6-7]. The return clearing is held through floppy based clearing by the close of the banking hours on the same day. With the introduction of RTGS \& other electronic payment sytem it lost its charm \& finally in March 2010, this clearing was discontinued.

\subsection{SPEED CLEARING:}

This clearing refers to the processing of the outstation cheques through local clearing. Usually the outstation cheques are sent for collection to the respective bank branches through post or courier. This cheque may take 7 to 21 days to clear and also may incur certain clearing charges [8]. This system was introduced in June 2008. This is a part of the existing MICR Clearing, the only difference is that we can clear cheques that are drawn on core banking branches which have a branch in that city.

\subsection{EXPRESS CHEQUE CLEARING SYSTEM (ECCS):}

Apart from the 66 cntres which used the MICR system, there were yet another 1,093 locations which were known as non-MICR centres. These centres were using the Magnetic Media Based Clearing Software (MMBCS) which helped these centres in automating the manual process of running these clearing houses [9]. With the growing need for improved technology along with the core banking \& graphic interface created pressure on RBI to go for something new. Hence in 2011 State Bank of India (SBI) under the advice of RBI along with the help of Software Company 
developed Express Cheque Clearing System (ECCS). This system helped the non-MICR centres to have a better control on the clearing activities.

\subsection{CHEQUE TRUNCATION SYSTEM} (CTS):

This is a logical progression of MICR clearing because the main problem with MICR system was the physical movement of cheques. With the main objective of increasing the efficiency and reducing the cheque processing time, the cheque truncation system (CTS) was introduced. CTS is an electronic process wherein the physical cheque is stopped at the presenting bank itself and only the electronic image of the check is passed on to the paying bank. The physical cheque remains with the presenting bank itself. The paying bank cheques the image \& clears the funds based on the information provided to them by the presenting bank in the form of electronic media. This system was first introduced on February 1, 2008 at NCR (National Capital
Region), New Delhi, and presently it has been rolled out in other major regions all over India through Grid system[10].

If we have a look at the various types of cheque clearing systems, they can be mainly segregated into the following three categories.

- Traditional and Manual Clearing system

- MICR Clearing system

- Cheque Truncation system

Let us see these in detail.

\section{TRADITIONAL AND MANUAL} CLEARING SYSTEM:

These systems were the old type wherein the manual work of the bank clerks and officers were prominent. It was a tedious work for them to carry the cheques and do the clearing activity. The time taken for this clearing type was more and it was also a costly affair. The risk of the instruments being lost in transit were also more

\section{- Cheque Format: (Traditional)}

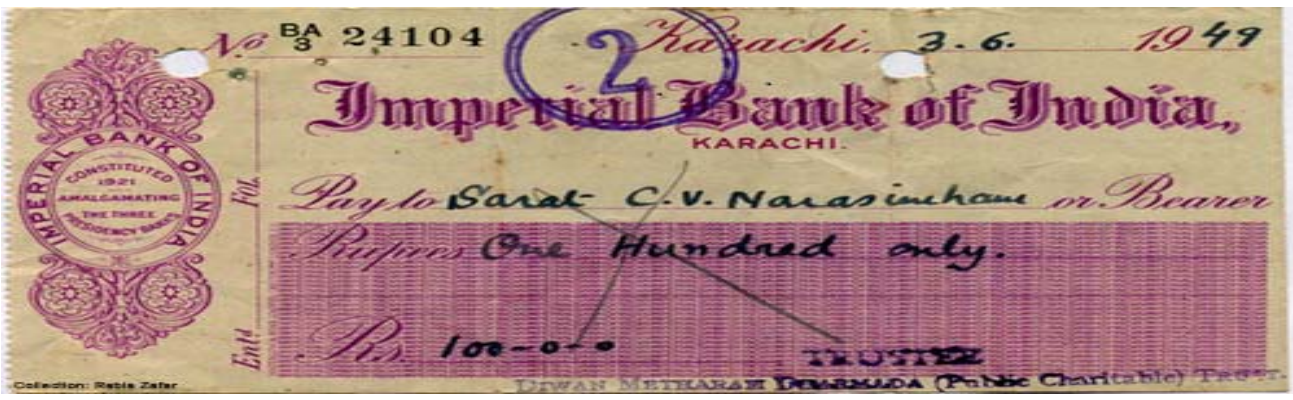

Figure 1: Format of Traditional Cheque

This is a format of a traditional clearing cheque, wherein each bank had its own format of printing the cheque [11]. There were no standardised fields or format for elements of the cheque.

Cheque Format ( Manual/Hand sorted)

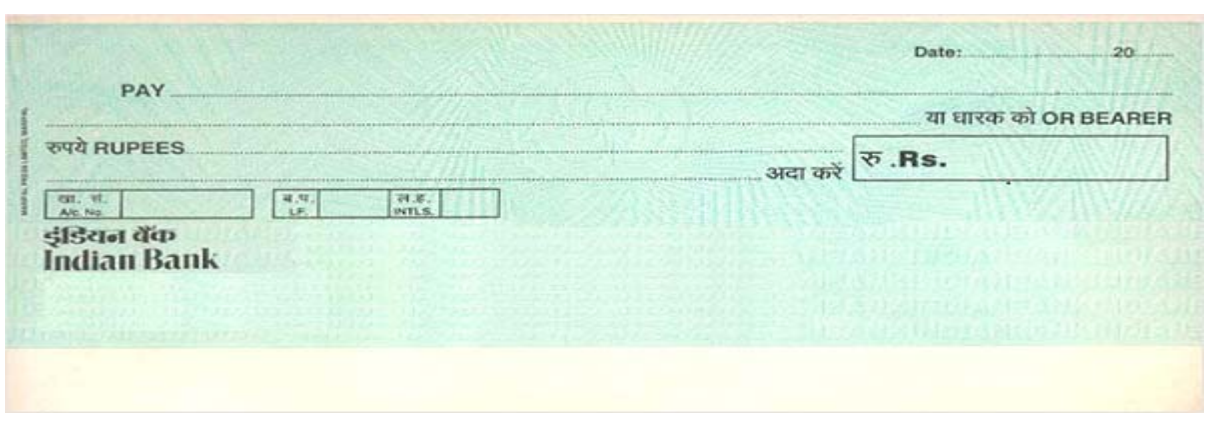

Figure 2: Format of Non-MICR cheque 
Then came the era of Hand-sorted or Manual clearing system, the above cheque shows the format of that era. This type of cheque is now popularly known as the Non-MICR cheque. These cheques were slightly better than the traditional or old aged era. Here there was a standard format for each elements of the cheque [12]. Still the branch names and other details such as account numbers were needed to be written or hand sealed. Slowly in the later stages of the era they started to have personalised cheques, whichwere cheques with name of the account holders and their account numbers being printed on them.

\section{MICR CLEARING SYSTEM:}

To overcome the shortcomings of the handsorted or manual clearing system a new system known as The Magnetic Ink Character Recognition (MICR) system was introduced. This system simplified the clearing process. It helped in sorting the cheques at a faster pace with the help of machines, which reads the MICR codes which were punched on them by the presenting banks. The MICR band has various information like the city, bank, branch and amount which are used by the clearing house to segregate and sort these cheques to various banks.

\section{Cheque Format:}

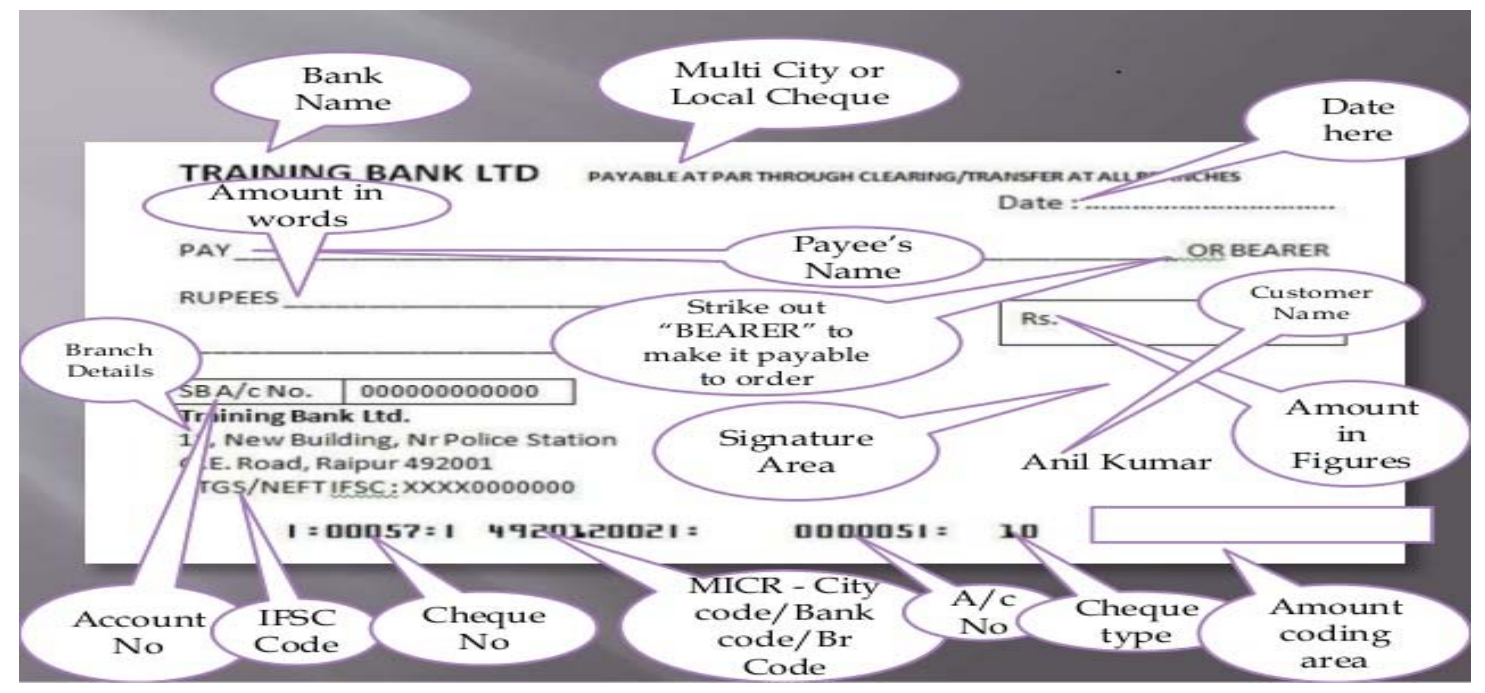

Figure 3 : Format of MICR cheque

The above format shows the description of the MICR cheque. The various elements of the cheque are standardised. It also includes the branch address and IFSC number of the branch and at the end there is the MICR band which gives the details regarding cheque number, city, bank, branch, cheque type etc. which helps in the faster processing of cheques in the clearing house.

\section{CHEQUE TRUNCATION SYSTEM:}

The main drawback of MICR clearing system was that in spite of the use of technology and increasing the processing speed there was the problem of physical movement of the cheques. This resulted in unnecessary wastage of time and money, also it increased the risk of frauds. To overcome all these problems a new system of clearing the Cheque Truncation System
(CTS) was introduced. This system stopped the physical movement of cheques at the presenting branch level itself and only the electronic image with other MICR details are transferred to the clearing house for settlement. This will further increase the efficiency of the clearing system by reducing the time and cost aspect involved in the previous systems [13-14]. This system also introduced a new standard format of cheque, which will further reduce the risk of frauds in the paper based clearing system.

\section{Cheque Format:}




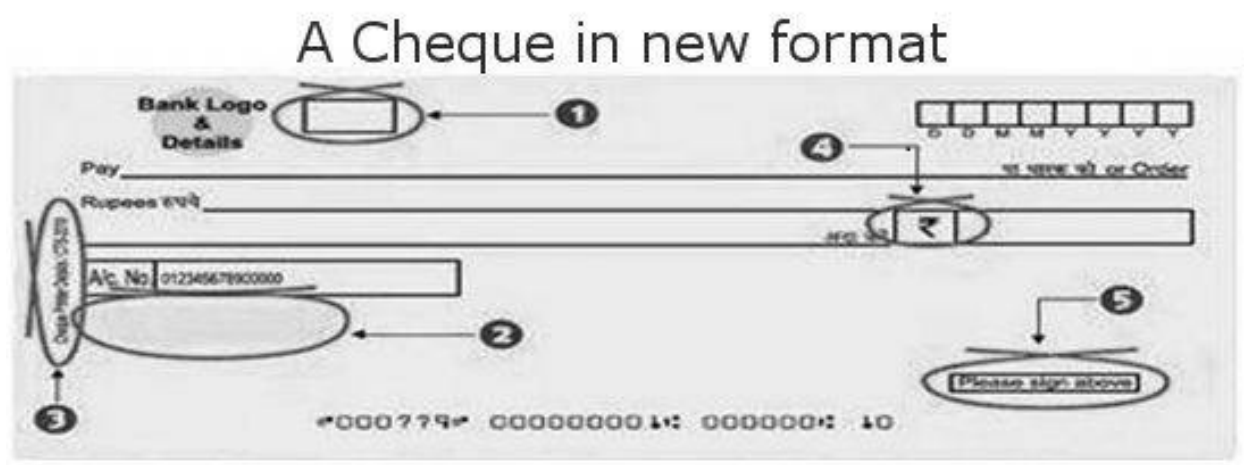

1. Bank's logo printed with invisible link (ultra-violet ink)

2. Void pantograph

3. Cheque printer details/CTS-2010

4. Symbol

5. Signature space indicator

Figure 4: Format of CTS-2010 cheque

The above format shows the new format which is known as "CTS-2010" cheque. These cheques have certain additional security measures as shown above. It has the banks logo printed in ultra violet (U/V) ink and it also has a void pantograph which denotes the cheque being CTS-2010 compliant.

\section{CONCLUSION:}

Cheque clearing is the most important activity of any banking institute. It is an activity based on which the funds are transferred from one person to another or in another terms it is the process by which a transaction is completed.

In this paper we have seen what payments are and the various types of payments. We focused more on the cheques or the paper based clearing activity, where in we saw the evolution of cheque clearing system. Also we briefly discussed the various types of cheque clearing systems that has evolved over time. From the traditional clearing system where the clerks use to go to various banks to clear and settle the dues to Hand-sorted system, where bank people use to meet at a central point and settle the difference through cash or central bank cheque. As the volumes increased along with technology the MICR system came into limelight which helped the processing of cheques at a faster pace and hence increased the efficiency of the cheque clearing system. In spite of all these changes the physical cheques were still moving from the presenting banker to the clearing house and finally to the settling banker. In order to avoid this and also to reduce the cost and time wasted with this activity a new system called Cheque Truncation System (CTS) is introduced. Presently this CTS system is in existence and is working on a grid clearing system. With CTS cheques from any core banking branch can be cleared at one go as a local clearing cheque.

In future we may also move towards the Remote Cheque Deposit system, which is prevailing in some of the countries. Through this system a person can take a photo of a cheque and send the image to their branch and ask the bank to process the instrument for payment without the physical instrument being presented by the customer.

Hence we conclude that cheque clearing has evolved over time from the traditional to the more modern CTS system, with the objective being fast, safe and secure.

\section{REFERENCES}

[1] Menezes, A. D.,\& Pinto, Prakash. (2015). Emergence of Cheque Truncation System. IJMIE, 5(7) 262-269

[2] Igbaria, M., \&Nachman, S. A. (1990). Correlates of user satisfaction with end user computing: an exploratory study. Information \& Management, 19(2), 73-82.

[3] Kelley, S. W., \& Davis, M. A. (1994). Antecedents to customer expectations for service recovery. Journal of the Academy of Marketing Science, 22(1), 52-61.

[4] Khurana, S. (2009). Managing service quality: an empirical study on internet 
banking. IUP Journal of Marketing Management, 8(3/4), 96.

[5] Ko, C. H., Hsiao, S., Liu, G. C., Yen, J. Y., Yang, M. J., \& Yen, C. F. (2010). The characteristics of decision making, potential to take risks, and personality of college students with Internet addiction. Psychiatry research, 175(1), 121-125.

[6] Iivari, J. (1997). User information satisfaction: A critical review. Encyclopedia of library and information science, 60 (Supplement 23), 341-364.

[7] Lassar, W. M., Manolis, C., \& Winsor, R. D. (2000). Service quality perspectives and satisfaction in private banking. Journal of services marketing, 14(3), 244-271.

[8] Legris, P., Ingham, J., \&Collerette, P. (2003). Why do people use information technology? A critical review of the technology acceptance model. Information \& management, 40(3), 191-204.

[9] Lin, W. T., \& Shao, B. B. (2000). The relationship between user participation and system success: a simultaneous contingency approach. Information \& Management, 37(6), 283-295.
[10] Mahmood, M. A., Burn, J. M., Gemoets, L. A., \& Jacquez, C. (2000). Variables affecting information technology end-user satisfaction: a meta-analysis of the empirical literature. International Journal of HumanComputer Studies, 52(4), 751-771.

[11] Oliver, R. L., Rust, R. T., \&Varki, S. (1997). Customer delight: foundations, findings, and managerial insight. Journal of retailing, 73(3), 311-336.

[12] Oppewal, H., \& Vriens, M. (2000). Measuring perceived service quality using integrated conjoint experiments. international journal of bank marketing, 18(4), 154-169.

[13] Parasuraman, A., Zeithaml, V. A., \& Berry, L. L. (1985). A conceptual model of service quality and its implications for future research. the Journal of Marketing, 41-50.

[14] Parasuraman, A., Zeithaml, V. A., \& Berry, L. L. (1988). Servqual: A multiple-item scale for measuring consumer perc. Journal of retailing, 64(1), 12. 